\title{
Analisis Kepuasan Konsumen dengan Uji Deskriptif dan PLS Pada PerusahaanMultifinace
}

\author{
Sonny Indrajaya dan Jarlest Andini Agustinanda \\ Fakultas Ekonomi dan Bisnis Universitas Mercu Buana \\ Email: \\ sonny.indrajaya@mercubuana.ac.id
}

\begin{abstract}
Abstrak: Penelitian ini tujuan untuk dapat menganalisis dan perusahaan multi finance di Kota Tangerang pengaruhnya kepada kepuasan pelanggan. Populasi untuk penelitian ini adalah sebanyak 145 responden, dihitung berdasarkan purposive sampling. Metode dalam pengumpulan data dengan menggunakan suatu metode survei, instrumen penelitian memakai kuesioner dengan skala likert. Metode untukmenganalisis data dengan menggunakan alat uji SPSS guna menguji deskriptif karakteristik pelanggan dan uji Partial Least Square untuk mendapatkan hasil hipotesis. Hasil yang didapat pada penelitian ini ada yang positif danjuga sangat signifikan dan ada hasil yang positif tetapi kurang siginifikankepada kepuasan pada pelanggan.
\end{abstract}

Kata Kunci: Kepercayaan, Fasilitas, Kualitas Pelayanan, Kepuasan Pelanggan.

\begin{abstract}
This study aims, to be able to analyze and multi-finance companies in Tangerang City their impact on customer satisfaction. The population for this study were 145 respondents, calculated based on purposive sampling. The method, of collecting data using a survey method, the research instrument using, a questionnaire with a Likert scale. Methods for analyzing data using the SPSS test tool to test descriptive of customer characteristics and Partial Least Square test to obtain hypothesis results. The results, obtained in this study are positive and also very significant, and there are positive results but less significant to customer satisfaction.
\end{abstract}

Keywords: Trust, Facilities, Service Quality, Customer Satisfaction.

\section{PENDAHULUAN}

Kegiatan multifinance dilakukan untuk menyediaan dana, modal jugamenyediakan barang untuk kebutuhan para konsumen dengan ini tidak dilakukannya penarikan dana yang secara langsung dari masyarakat dengan melalui tabungan dan giro, ataupundalam bentuk lainnya yang dapatdisamakan. Kegiatan ini yang bisa memberikan perbedaan usaha multifinance dengan usaha dari perbankan, dimanaini jenis usahanya sama dari lembaga keuangan. Penarikan dana langsung dari masyarakat (deposit taking activity) oleh suatu bank, tetapiuntuk usaha multi finance tidak dapat melakukan suatu penarikan dana secara langsung kepada masyarakat. Multifinance adalah suatu usaha yang bidangnya lembaga keuangan bukan bank dan memiliki peranpenting untuk pembiayaan serta melakukan 
bentuk pengelolaan yang merupakan jadi pilihan sumber dana bagi pembangunan Indonesia, ini sudah terbukti sebagai entitas bisnisyang ada manfaat yang besar di dunia usaha kecil, dan usaha menengah juga untuk usaha besar.

Perusahaan Multi Finance di Kota Tangerang merupakan jasa leasing. Suatu usaha leasing dapat termasuk dalam salah satu suatu bentuk lembaga pembiayaan, inidikarenakanlembaga pembiayaan merupakan, suatu usaha yang dilakukannya untuk suatu pembiayaan dengan menyediakan dana atau juga barang modal dan tidak bisa untukpenarikan dana yang langsung ke masyarakat. Leasing merupakansuatu kegiatan usaha di pembiayaan dan menyediakan barang modal yang dapat digunakan untuk jangka waktu terterntu oleh perusahaan. Pembayaran yang dilakukan secara berkala dan juga disertakan dengan hak memilih untuk perusahaan guna membeli pada barang modal atau juga bisa diperpanjang jangka waktu leasing yang didasarkan pada nilai sisa yang telah disepakati secara bersama, maka usaha leasing termasuk pada salah satu jenis lembaga pembiayaan, hal ini dikarenakan leasing akan membiayai perusahaan dengan bentuk penyediaan barang modal.

Tabel 1. Penurunan Penjualan ProdukMultifinance Tahun

\begin{tabular}{c|c|c}
\hline Tahun & Target penjualan (unit) & Volume Penjualan (unit) \\
\hline 2014 & 600 & 603 \\
\hline 2015 & 550 & 410 \\
\hline 2016 & 500 & 400 \\
\hline 2017 & 500 & 350 \\
\hline 2018 & 450 & 370 \\
\hline 2019 & 400 & 385 \\
\hline
\end{tabular}

Sumber: Multi Finance (2019)

Penurunan penjulan produk Multi Finance menyebabkan biaya operasional lebih besar, sehingga menimbulkan kerugian. Menurunnya jumlah penjualan produk di Tahun 20142019 disebabkan adanya kekhawatiran dari konsumen yang merasa kredit di Multi Finance belum terjamin.

Tabel 2.Keluhan Data Kotak SaranMulti Finance Tahun

\begin{tabular}{c|l|c}
\hline No & \multicolumn{1}{|c}{ Pernyataan } & Hasil (\%) \\
\hline 1 & Kurang tesianya wifi & $70 \%$ \\
\hline 2 & Kurang tersedianya parker yang luas & $80 \%$ \\
\hline 3 & Kurang banyak tersdianya bangku untuk menunggu antrian & $75 \%$ \\
\hline 4 & Karyawan tidak detail memberi informasi & $60 \%$ \\
\hline 5 & Karyawan tidak cepat melayani konsumen & $75 \%$ \\
\hline 6 & Konsumen merasa kurang puas setelah transaksi & $77 \%$ \\
\hline
\end{tabular}

Sumber: Kotak Saran (2019)

Dijelaskan bahwa data tersebut diperoleh dari kotak saran Multi Finance setelah melakukan transaksi, rata-rata mengeluh masalah fasilitas dan pelayanan yang kurang 
strategi secara khusus dimana konsumendapat pinda memakai produk atau jasa perusahaan dari pada competitor.

\section{KAJIAN TEORI}

Pengertian Pemasaran. Pendapat (Kotler, 2016) menyatakan dalam pemasaran terdapatkegiatan juga mengatur lembaga serta proses untuk menciptakan, mengadakan komunikas dan menyampaikan juga dapat bertukar penawaran yang memiliki nilai bagi pelanggan atau dan juga untuk masyarakat umumnya.

Kepercayaan. Patmala (Lestari, 2016) memiliki pendapat suatu kepercayaan merupakan kesediaan pada perusahaan yang bergantung kepada mitra bisnis dimana kepercayaan itu akan tergantung kepada faktor-faktor hubungan antar pribadi dan juga antarorganisasi, contohnya kompetensi atau integritas, bisa juga kejujuran, dan dalam bentuk kebaikan hati perusahaan. Kepercayaan secara arti bahasa adalah suatu keyakinan pada sesuatu yang dapat dipercaya bahwa itu benar dan sesuai kenyataan, untuk arti secara istilah kepercayaan adalah menganggap itu pasti yang dikatakan dengan jujur danakan memenuhi harapannya, dapat juga diartikan sebagai suatu ekspresi dasar yang akan menggambarkan suatu kesetiaan. Kotler dan Keller (2016) memberi suatu definisi untuk kepercayaan adalah diaman kesediaan pihak pada perusahaan untuk bisa mengandalkan kepada mitra bisnis. Kepercayaan akan tergantung ke sejumlah faktor secara interpersonal dan juga antar organisasi, dengan contohnya kompetensi perusahaan dan integritas juga kejujuran, kebaikan.

Faktor yang dapat memberikan pengaruh kepada kepercayaan. (Fainnadewi, 2013) memiliki pendapat konsumen akan dapat percaya ke perusahaan, maka diperlukan faktor yang dapat mempemgaruhi kepercayaan:

Achieving result. Konsumen memiliki harapan untuk janji-janji dari perusahaan, ini harus dipenuhi bila ingindapatkan kepercayaan dari konsumen, dimana suatu kepercayaan konsumenakandapat ditumbuhkan dengan menepatu janji oleh pihak peruhaan.

Acting with integrity.Tindakan secara integritas dimana terdapat konsistensi antara diucapkan dengan tindakan disetiap situasi. Suatu integritas adalah suatuyang menjadi faktor kunci untuk dapat dipercaya secara benar dari pihak lain dengan semua yang diucapkan harus sesuai dengan tindakannya.

Demonstrate concern. Kemampuan yang dimiliki perusahaan untuk dapat memberi perhatian kepada konsumen dengan menunjukkanpengertian kepada konsumen drngan contoh konsumen bila menghadapi suatu masalah dengan produknya, maka perusahaan harus memberi perhatiannya, dimana akan menumbuhkan kepercayaan.

Fasilitas. Pendapat (Tjiptono dan Gregorius, 2016) fasilitas adalah suatu bentuk fisik atau atmosfir yang terbentuk oleh eksterior dan interior yang sudah disediakan oleh perusahaan untuk membangun rasa aman, nyaman bagi pelanggan. Fasilitas merupakan bentuk dari kebendaan yang memiliki fungsi mengubah pada nilai suatu produk juga layanan jasa. Fasilitas pelayanan pada jasa ada hal-hal yangperlu menjadi perhatian: kebersihan dan 
kerapihan fasilitas juga kondisi serta pada fungsi fasilitas, kemudahannya dalam menggunakan fasilitas, juga untuk kelengkapan pada perlengkapan yang ditawarkan

Faktor-faktor yang memliki pengaruh terhadap Fasilitas. (Tjiptono, 2010) mengatakan untuk desain juga tata letak fasilitas jasa, akan erat berkaitan dengan terbentuknya persepsi pelanggan. Ada beberapa tipe jasa yang dapat membentuk persepsi, ini terjadi pada interaksi antara pelanggan yang menggunakan fasilitas yang adapengaruhnya kepada kualitas suatu jasa dimata para konsumen.

Beberapa faktor yang memiliki pengaruh yang signifikan kepada desain fasilitas pada jasa: (1) Sifat, tujuan organisasi pada jasa akan sangat menentukan persyaratan desainnya, contoh pada ruang peralatan harus representatif, ruang memilikikenyamanan dan bersih untuk pelanggan dalam mengajukan kredit. Pada desain untuk fasilitas agarmemberikan manfaat, dimana perusahaan bisa gampang dikenali dan untuk desain interior harus mencirikan yang khas dan memberikan mengarahkan akan sifat jasanya. (2) Memiliki lahan tanah dan dapat memenuhi ruang dan juga tempat. Perusahaan jasa harus ada area untuk fisiknya dan sarana fasilitas jasa. Penentuan lokasi akan diperhatikan faktor kemampuan keuangan, peraturan pemerintah ( $\mathrm{pp}$ ) yang mengatur kepemilikan suatu lahan dan juga mengatur dalam membebaskan tanah, serta lainnya. (3) Faktor fleksibilitas desain diperlukan bila jumlah permintaan berfluktuasi juga spesifikasinya pada jasa yang cepat dikembangkan, maka untuk resiko yang besar pada keuangan. Kedua kondisi pastinya dapat menjadi peyebab fasilitas jasa akan dapat disesuaikan terjadinya perkembangan diwaktu akan datang. (4) Faktor diestetis untuk fasilitas dijasa harus dirapikan dan menarik, ini dapat memberikan peningkatan sikap yang positif dari pelanggan pada jasa, aspek lainnya karyawan kepada pekerjaan dan motivasi kerja karyawan meningkat. Aspek yang memerlukan penataan juga ada aspek lain contoh ketingian plafon bangunan, posisi pintu danjendela, dengan desain berbagai ragam, dan juga dekorasinyadiinterior. (5) Pembiayaan pembanguan dan danaoperasi, pembiayaan ini dapat mempengaruhi desain untuk fasilitas. Biaya untuk konstruksi pada bangunanakan memberikan pengaruhnyapada jumlahnya dan juga jenisnya pada bangunan yang akan dipakai. Dana atau biaya untuk operasi akan ditentukan oleh kebutuhan untuk energi listrikpada ruangan dan perubahan suhu.

Kualitas Pelayanan. Memiliki perbandingan diantara pelayanan yang diharapkan dengan yang akan diterima oleh konsumen. (Tjiptono, 2014). Kualitas di jasa adalah pengukuran seberapa bagusnya pada levelpelayanan bisa memberikan yang setara seperti yang diharapkan konsumennya. Pengertian inimemiliki kesimpulan kualitas layanan suatu bentuk kegiatan ekonomi yang hasil akhirnya bukan produk konsumsi, waktu produksi tetapi dapat memberikan suatu nilai tambah akan kenikmatan, hiburan yang sifatnya tidak berwujud dan nantinya jasa diterima oleh pelanggan akan sesuai dengan diharapkan. Oleh karena itu kualitas pelayanannya dapat diperkirakan baik, ideal dan bisa sebaliknya bila suatu pelayanan yang diterimakan lebih jelek dibandingkan dengan diharapkan oleh konsumen, ini berarti kualitas pelayanan akan dipersepsikan jelek, tidak ideal, sehingga kebutuhan konsumen bisa dipenuhi. 
Faktor yang memberikan pengaruh pada kualias pelayanan. (Tjiptono, 2009) memiki pendapat ada empat faktor dominan dalam kualitas jasa :

1) Design quality. Kualitas pelayanan akan ditentukan pada desaian pertama kali pelayanan agar dapat terpenuhi kebutuhan pelanggan.

2) Production quality. Menjelaskan penetuan kualitas pelayanan ditentukan kerja sama di departemen pemasaran.

3) Delevery quality. Kualitas jasa akan ditentukan akan janji-janji perusahaan yang diberikan ke pelanggan.

4) Relationshop quality, akan ditentukan oleh hubungan yang profesional dan sosial antara perusahaan dengan pelanggan dan pemasok juga para agen, serta pemerintah, karyawan perusahaan.

Kepuasan Pelanggan. (Kotler dan Keller, 2016) memiliki dafinis kepuasan yaitu suatu perasaan yang puas atau juga kecewa, ini dihasilkan dari memperbandingkan diantara performa dari produk dengan yang diekspektasi konsumen, jika performa perusahaan kurang dari ekspektasimaka pastinya konsumen kecewa dan sebaliknya bila ini sesuai dengan diharapkan oleh konsumen maka merasakankepuasan.

Faktor-faktor yang bisamemberikan pengaruh kepuasan pada pelanggan. (Lupiyoadi, 2001).Terdapat tiga faktor utama yang harus menjadi perhatian yangberkaitan dengan kepuasan pelanggan: (1) Kualitas Produk. Pelanggan akan merasa puas bila untuk hasil evaluasinya menunjukan produknya atau jasa yang mereka sudah gunakan memiliki kualitas. (2) Kualitas Pelayanan. Kepuasan dipelanggan akan terpenuhi bila sudah mendapatkanpelayanannyasudah sesuai harapan. (3) Emosional. Kebanggaan dan kepuasan juga keyakinanyang didapat bila seseorang atau orang banyak menggunakan produk atau jasa yang bermerek dan juga cenderung memiki kepuasan lebih meninggi. Kepuasan didapat tidak hanya oleh kualitas dari produk juga ditentukan oleh nilai sosial yang memberikanpara pelanggan merasa puas pada merk-merk tertentu.

\section{Hubungan Antar Varibel dan Hipotesis}

\section{Pengaruh Kepercayaan terhadap Kepuasan Pelanggan.}

Kepercayaan merupakan dal yang diyakini oleh seseorang dimana akan ditemukan yang diinginkan. Kepercayaan akan turut melibatkan kesediaan pada seseorang untuk dapat melakukan tingkah laku tertentu, hal inidikarenakan keyakinan bahwa mitranya bisa memberikan yang diharapkan yang berupa kata dam janji juga pernyataan yang dapat dipercaya. Kepercayaan pelanggan akan mencerminkan untuk semua pengetahuan yang dimiliki konsumen yanga membuat kesimpulan tentang objek, atribut, dan manfaatnya. Hasil penelitian ini diperkuat denganpenelitian oleh Khusdil Chhabra (2018). Kepercayaan akan memiliki pengaruhnya yang positif dan juga yang signifikan kepada kepuasan di pelanggan dan hasil pada penelitian lainnya di lakukan oelh IB Ngurah Satwika Purwa dan IG Agung Ketut Sri Ardani (2018) menyatakan untuk kepercayaan akan memilikipengaruhnyayang positif juga signifikan kepada kepuasan diantara pelanggan. 
Hipotesis H1: Kepercayaan berpengaruh positif dan signifikan terhadap kepuasan pelanggan.

Pengaruh Fasilitas terhadap Kepuasan Pelanggan. (Tjiptono, 2014) memaparkan untuk fasilitas merupakan sumber daya secara fisik yang diadakansebelumnya suatu jasa akan tawarkan ke pelanggannya. Fasilitas bisa berupa sesuatu dandapat memberikan kemudahan kepada konsumen untuk mendapatkan kepuasan, dimana bentuk dari jasa itu tidak akan bisa dilihat dan tidak bisa juga dicium juga tidaklah bisa untuk diraba, dari itu aspek berbentuk fisik menjadikanhal yang terpenting dariukuran pelayanan. Para konsumen akan bisa memakai indera penglihatannya dalam memberikan penilaian kualitas pelayanan.

Fasilitas memberikan pengaruhsecara signifikan terhadap kepuasan konsumen. Semakin baiknya fasilitas yang apsti diberikan perusahaan akan semakin tinggi juga tingkat kepuasan dari pelanggan, hal ini dikarenakan konsumen akan melihat perusahaan pemberi jasa dari fasilitas yang diberikan untuk dapat memenuhi kebutuha. Penelitian inisejalan dengan penelitian (Radevino dan Eko, 2019) yang megatakan bahwa fasilitas memiki pengaruh yang positif terhadap kepuasan pelanggan dan penelitian lain oleh (Sartika dan Sjendry, 2016). Fasilitas memberikan pengaruh positif juga signifikan kepada kepuasan si pelanggan.

Hipotesis H2: Fasilitas berpengaruh positif dan signifikan terhadap terhadap kepuasan pelanggan

Pengaruh Kualitas Pelayanan terhadap Kepuasan Pelanggan. Kualitas memiki dorongan ke pelanggan agar dapat menjalin hubungan yang kuat dengan perusahaan. Waktu jangka panjang untuk ikatan ini dapat dimungkinkan bahwa perusahaan untuk memahami dengan benarakan diharapkan dan dibutuhkan dari pelanggan agar perusahaan bisa meningkatkan kepuasan kepada pelanggan dengan secara memaksimalkan pengalaman dari pelanggan yang menyenangkan juga meminimalkan pengalaman si pelanggan yang kurang menyenangkan. Menurut (Sembiring et al., 2014). Secara bersama atau secara keseluruhan dimensi dari kualitasnya untuk pelayananakan ada pengaruhnya secara signifikan pada kepuasan pelanggan. Hasil penelitian ini juga sejalan dengan (Jamal dan Ala, 2018) mengatakan hasilnya kualitas di pelayanan positif serta signifikan pada kepuasan si pelanggan. Hasil lain yang juga dilakukan (Minth dan Nguyen, 2016) mengemukakan kualitas pelayanan memiki pengaruh positif dan juga signifikan kepada kepuasan pelanggan.

Hipotesis H3: Kualitas pelayanan berpengaruh positif dan signifikan terhadap kepuasan pelanggan 
Gambar 1. Rerangka Konseptual

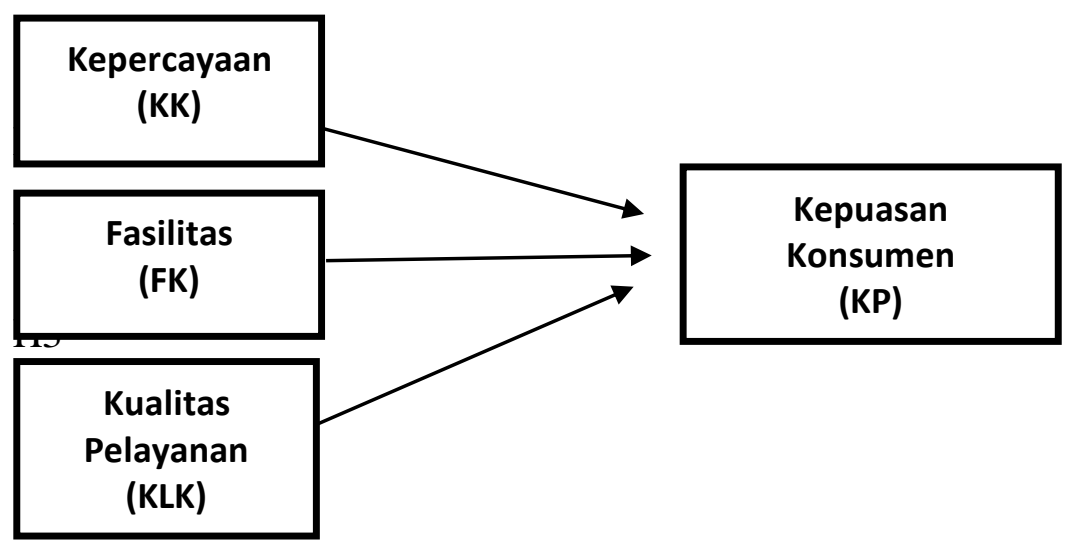

Sumber: Olah Data, (2019)

\section{METODELOGI}

Waktu dan Tempat Penelitian. Proses penelitian dari September 2019 - Juli 2020. Penelitian ini akan dilakukan di Kota Tangerang. Objek penelitian ini adalah pelanggan pengguna jasa Perusahaan Multi Finance cabang kota Tangerang.

Desain Penelitian. Jenis di penelitian ini bisa digolongkan dalam penelitian kuantitatif dimana mode penelitiannya dilandaskan pada filsafat positivme, yang akan dipakai untuk meneliti sampel dan populasi penelitian. Teknik yang digunakan dalam pengambilan pada sampelnya dilakukan secara acak atau random sampling. Dalam mengumpulkan data dengan memakaiinstrumen penelitiannya agarbisa dipergunakan, untuk analisis datanyaakandigunakan secara kuantitatif yang dapat diukur, ini dengan tujuandapat diuji hipotesis (Sugiyono, 2016).

Populasi. (Sugiyono, 2016) yang mengatakan populasi sebagai suatu wilayah pada generalisasi terdiri objek atau jugasubjek dan menjadikan kuantitas juga karakteristik yang tertentu yang sudah ditetapkan oleh peneliti untuk dapat dipelajari dan dapat diambil kesimpulan, maka populasinya merupakan keseluruhan subjek penelitiannya. Pada penelitian ini, populasi yang digunakan adalah pengguna atau pelanggan jasa Perusahaan Multi Finance di Kota Tangerang yang sudah melakukan kredit lebih dari 2 kali dan memiliki umur 21-58 tahun.

Sampel. Merupakan sebagian jumlah, karakteristik didalam populasi. Sampel diambil oleh peneliti akan melakukan penelitian pada populasi yang memiliki jumlahnya besar, namun ini memiliki keterbatasan baik dana dan tenaga juga waktu. Sugiyono (2016) Menggunakan teknik untuk pengambilan sampel akan membentuk generalisasi kepada populasi yang ditelitinya. Sampel yang diambil dapat mewakili populasi tersebut. 
Teknik yang dipakai di penelitianini dengannon probability Sampling. Ungkapan Sugiyono (2016), non-probability sampling merupakan suatu teknik dalampengambilan pada sampel dengan tidak akanmemberi peluang atau kesempatan yang sama untuk setiap unsuratau anggotapopulasi yang dapat dipilih dan dijadikan sampel. Pengambilan untuk sampel akan dilakukan secara purposive sampling. Menurut (Suiyono, 2016) Purposive samplingmemiliki arti teknik pada penentuan sampel,memakai pertimbangan yang tertentu. Pertimbangannyadigunakan sampel di penelitian ini para pelanggan yang telah menggunakan jasa perusahaan multi finance dengan umur 21 tahun keatas.

Penentuan jumlah sampel dengan memakai teori (Hair et al., 2014) menyatakan ukuran sampel untuk analisis SEM akan tergantung kepada jumlah parameter yang akan diukur dimana pada sampel akan didapat 5-10 dikali jumlah parameter yang diestimasai (diukur). Penulis menetapkan jumlah sampel:Jumlah sampel $=5 \mathrm{x} \mathrm{n}$ (parameter yang diestimasi) maka 5 x $29=145$. Jumlah untuk sampel akan dipakaididalam penelitian ini berjumlah 145 responden.

Metode Analisis. Penelitianini memakai metode secara analisisdimana data diolah secara kuantitatif, dimana penelitian kuantitatif, analisis data dipakai untukmenjawab padarumusan masalah dan juga untukdapat menguji hipotesis yang sudah dirumuskan sebelumnya.

Analisis Deskriptif. (Ghozali, 2014), memiliki pendapat analisis deskriptif bisa digunakan untukanalisis datanya, caranya dengan mendeskripsikan atau menggambarkan pada datayang telah terlebih dikumpulkan dan tidak untuk diambilkesimpulan serta berlaku secara umumatau generalisasi. Pada analisisdeskriptif ini tidak akan ada uji yang signifikasi dan tidak juga ada taraf dikesalahan, hal inidikarenakan penulisi sebagai penelititidak ada maksud membuatnya secara generalisasi, sehingga tidakakan ada suatu kesalahansecara generalisasi.

Partial Least Square (PLS). Dalam melakukan pengujian hipotesis dan untuk mendapatkan hasil untuk suatu model yang layak atau fit,maka metode analisis menggunakan Component atau namanya Variance Based Structural Equation Modeling yanag dalam mengolah data dengan menggunakan program analisa Partial Least Square (PLS).versi yang merupakan model alternative dari covariance based SEM. Penggunan PLS memiliki maksud untuk menganalisis causal-perdictive di situasi kompleksitas yang tinggi dan juga harus dapat dukungan teori yang rendah (Ghozali, 2013). Tujuanpenggunaan PLSuntuk bisa mencari hubungan yang linear prediktif dengan optimal pada data. PLS juga bisa dipakai untuk mengkonfirmasikan suatu teori, namun digunakan juga bisa digunakan untuk dapat menjelaskan ada atau tidak hubungan diantara variable latennya. 


\section{HASIL DAN PEMBAHASAN}

\section{Deskripsi Responden}

Tabel 3. Karakteristik Responden- Jenis Kelamin

\begin{tabular}{l|l|l|l|l|l}
\hline & & Frequency & Percent & Valid Percent & $\begin{array}{l}\text { Cummulatif } \\
\text { Percent }\end{array}$ \\
\hline \multirow{3}{*}{ Valid } & Laki-laki & 75 & 51.5 & 51.7 & 51.7 \\
\cline { 2 - 6 } & Wanita & 70 & 58.3 & 48.3 & 100.0 \\
\cline { 2 - 6 } & Total & 145 & 100.0 & 100.0 & \\
\hline
\end{tabular}

Sumber: Olah Data (2020)

Tabel 4. Karakter Responden - Usia

\begin{tabular}{l|l|l|l|c|c}
\hline & Usia & Frequensy & Percent & Valid Precent & Cumulative Percent \\
\hline \multirow{4}{*}{ Valid } & $21-30$ & 100 & 69.0 & 69,0 & 69.0 \\
\cline { 2 - 6 } & $31-40$ & 36 & 24.8 & 24.8 & 93.8 \\
\cline { 2 - 6 } & $41-50$ & 1 & 7 & 7 & 94.5 \\
\cline { 2 - 6 } & $51-58$ & 8 & 5.5 & 5.5 & 100.0 \\
\cline { 2 - 6 } & Total & 145 & 100.0 & 100.0 & \\
\hline
\end{tabular}

Sumber: Olah Data (2020)

Didapatkanresponden memiliki untuk tingkat usia aau umur yang berbeda, usia paling banyak dari responden 21 tahun - 30 tahun dan yang terendah 41 tahun - 50 tahun.

Tabel 5. Karakteristik Responden -Pekerjaan

\begin{tabular}{l|l|l|l|l|l}
\hline & \multicolumn{1}{|c|}{ Pernyataan } & Frequensy & \multicolumn{1}{|c|}{ Percent } & Valid Percent & $\begin{array}{c}\text { Cumulative } \\
\text { Percent }\end{array}$ \\
\hline \multirow{5}{*}{ Valid } & Ibu Rumah Tangga & 26 & 17,9 & 17.9 & 17.9 \\
\cline { 2 - 6 } & Pegawai Swasta & 52 & 35.9 & 35.9 & 36.6 \\
\cline { 2 - 6 } & Pelajar/Mahasiswa & 15 & 10.3 & 10.3 & 82.8 \\
\cline { 2 - 6 } & PNS & 1 & 7 & 7 & 83.4 \\
\cline { 2 - 6 } & Pengusaha/Wurausaha & 24 & 16.6 & 16.6 & 36.6 \\
\cline { 2 - 6 } & Lainnya, sebutkan.. & 27 & 18.6 & 18.6 & \\
\cline { 2 - 6 } & Total & 145 & 100.0 & 100.0 & 36.0 \\
\hline
\end{tabular}

Sumber: Olah Data (2020) 
Menunjukkan bahwa dari 145 responden terdapat status pekerjaan yang paling banyak sebesar 52 responden atau sebesar 35,9\% dan paling terendah status pekerjaan PNS sebesar 1 atau sebesar 7\%. Data diatas dapat dilihat bahwa sebagian besar pelanggan berstatus pekerjaan pegawai swasta yang kredit.

Tabel 6. Karakteristik Responden - Penghasilan

\begin{tabular}{l|l|l|l|l|l}
\hline & & Frequensy & Percent & $\begin{array}{l}\text { Valid } \\
\text { Percent }\end{array}$ & $\begin{array}{l}\text { Cumulative } \\
\text { Percent }\end{array}$ \\
\hline \multirow{4}{*}{ Valid } & $\begin{array}{l}\text { Rp.1.700.000 - } \\
\text { Rp. } 4.000 .000\end{array}$ & 26 & 17.9 & 17.9 & 17.9 \\
\cline { 2 - 6 } & $\begin{array}{l}\text { Rp. } 4.100 .000- \\
\text { Rp. } 6.000 .000\end{array}$ & 52 & 35.9 & 35.9 & 36.6 \\
\cline { 2 - 6 }$>$ Rp.^.100.000 & 15 & 10.3 & 10.3 & 82.8 \\
\cline { 2 - 6 } & Total & 145 & 100.0 & 100.0 & \\
\hline
\end{tabular}

Sumber: Olah Data (2020)

Terlihat bahwa responden memiliki pekerjaan berbeda-beda, yang terbanyak adalah responden berpenghasilan Rp.1.7000.000 - Rp.4.000.000.

Hasil PengujianpadaDiscriminant Validity. Melihat discriminat validity dengan cara melihat dari nilai pade square root of average variance extracted (AVE) disetiap konstruknya dengan korelasi antara konstruk yang satu dengan konstruk di lainnya, hal ini dapat dikatakan sudah memiliki nilai discriminant validitynya yang sudah baik. Dalam menilai validitas apad suatu konstruk dapat melihat di nilai AVE, ini harus memenuhi persyaratan untuk jadi model yang baik, persyaratannya jika AVE masing-masing sudah memiliki nilai konstruk lebih besar dari 0,5 .

Tabel 7. Hasil Uji Average Variance Extracted (AVE)

\begin{tabular}{c|c}
\hline Variabel & AVE \\
\hline Kepercayaan & 0.612 \\
\hline Fasilitas & 0.670 \\
\hline Kualitas Pelayanan & 0.604 \\
\hline Kepuasan Pelanggan & 0.670 \\
\hline
\end{tabular}

Sumber: Olah Data (2020)

Nilai konstruk untuk semua variabel yaitu Fasilitas, Kepercayaan dan Kualitas Pelayanan juga Kepuasan Pelanggan harus sudah memiki nilai diatas 0,5 dimana diketahui bahwa nilai untuk Average Variance Extracted (AVE) tidak kurang atau lebih dari 0,50. 
Hasil pada tabel 7 dapat diambil kesimpulan bahwa tidak ada lagi masalah untuk uji convergent validity sehingga dapat dilakukan pengujian selanjutnya.

Tabel 8. Ujian Discriminant Validity (Fornell Larcker Criterium)

\begin{tabular}{l|l|l|l|l}
\hline & Frequensy & Kepercayaa & $\begin{array}{l}\text { Kualitas } \\
\text { Pelayanan }\end{array}$ & $\begin{array}{l}\text { Kepuasan } \\
\text { Pelanggan }\end{array}$ \\
\hline Fasilitas & 0.798 & & & \\
\hline Kepercayaan & 0.420 & 0.782 & & \\
\hline Kepuasan Pelanggan & 0.521 & 0.542 & 0.819 & \\
\hline Kualitas Pelayanan & 0.546 & 0.686 & 0.574 & 0.816 \\
\hline Sumber: Olah & & & &
\end{tabular}

Sumber: Olah data (2020)

Berdasarkan tabel 8 didapat untuk nilai Fornell Lacker Criterium padadisetiap konstruknya harusnya sudah lebih besar dari pada korelasi, antara konstruk yang satu dengan konstruk yang lainnya pada model, untuk nilainya yang didapat untuk konstruk dalam model ini yang sudah diestimasi dapat dikatakan memenuhi kriteria driscriminant validity.

Pengujian Composite Reability dan Cronbatch Alpha. Pada ujicomposite reabilitybila untuk seluruh nilainya di variabel laten yang sudah memiliki suatu nilai composite reability ataupun cronbrachs alpha $>0,7$, Ini diartikan bahwa untuk konstruk telahmemiliki reliability yang sudah baik atau dikatakan juga untuk kuesionernya yang dipakai untuk alat pada penelitian ini sudah andal (konsisten) (Ghozali, 2014). Hasil uji reliability pada tabel dibawah ini.

Tabel 9. Uji Reliabilitas (Composite Reability)

\begin{tabular}{l|l|l}
\hline \multicolumn{1}{c|}{ Variabel } & \multicolumn{1}{c|}{$\begin{array}{c}\text { Composite } \\
\text { Reliability }\end{array}$} & Keterangan \\
\hline Fasilitas & 0.897 & Reliabel \\
\hline Kepercayaan & 0.863 & Reliabel \\
\hline Kualitas pelayanan & 0.908 & Reliabel \\
\hline Kepuasan Pelanggan & 0.859 & Reliabel \\
Sumber: Olah data (2020) &
\end{tabular}

Hasil ujiComposite Realibilitysudah dapat menunjukkan nilai-nilai yang memuaskan, pada keseluruhan variabel latennya telah mempunyai untuk nilai composite realibility lebih 0.7 , untuk hasil di atas dapat terlihat untuk nilai composite realibility sudahmemenuhi kriteria. 
Tabel 10. Uji Reliabilitas (Cronbach's Alpha)

\begin{tabular}{l|l|l}
\hline Variabel & $\begin{array}{c}\text { Croncbach's } \\
\text { Alpha }\end{array}$ & $\begin{array}{l}\text { Keteranga } \\
\mathbf{n}\end{array}$ \\
\hline Fasilitas & 0.859 & Reliabel \\
\hline Kepercayaan & 0.788 & Reliabel \\
\hline Kualitas pelayanan & 0.873 & Reliabel \\
\hline Kepuasan Pelanggan & 0.754 & Reliabel \\
\hline Sumber: Olah Data (2020) & \multicolumn{2}{|l}{}
\end{tabular}

Pengujian untukcronbach's alpha telah memperlihatkan dan menunjukkan nilai-nilai yang sudah memuaskan, untuk keseluruhan pada variabel laten sudah mendapatkan nilai cronbach's alphayang lebih dari 0,7, maka untuk hasil diatas dapat dikatakan nilai cronbach's alphasudah memenuhi persyaratan dan kriteria.

Pengujian Model Structural / Uji Hipotesis (Inner Model).Ujian yang dilakukan untuk inner model merupakan suatu pengembangan suatu model yang basisnyadari konsep dan juga teori, ini agar dapat menganalisis suatu hubungan antara variabel eksogen dengan endogen, seperti yang dijabarkan pada kerangka konseptual. Pada langkah atau tahapan pada uji model structural (inner model), dapat dilakukan dengan tahapan / langkah ini:

Nilai R- Square. Untuk uji dilangkah yang kedua bisa dapat dilihatkan dari hasil $\mathrm{R}$ pada variabel laten untuk endogen nilainya 0.67 dan, $0.33,0.19$ didalam model structuralnya yang bisamemberikan indikasi untuk model tersebut baik atau moderat bisa juga lemah. Tabel nilai R- Square pada tabel 11:

\section{Uji R-Square (inner model)}

Tabel 11. Uji R- Square

\begin{tabular}{c|c}
\hline Variabel & R-Square \\
\hline Kepuasan Pelanggan & 0,941 \\
\hline Sumber: Olah data (2020)
\end{tabular}

Tabel 11 bisa diketahui untuk nilai $\mathrm{R}$ Square divariabel kepuasan pelanggan besarnya0,941. Ini memiliki arti variabel Fasilitas, Kepercayaan dan Kualitas Pelayanan adapengaruh kepada Kepuasan Pelanggan: 94,1\% sedangkan sisanya:5,9\% akan dapat pengaruhnya dari variabel lain yang tidak ikut diteliti didalam penelitian ini.

Goodness of Fit Model (GoF). Memberigambaran untuk tingkat kesesuaian di model dan secara keseluruhansudah dihitung untukresidual kuadratnya pada model yang akan diprediksi sertadiperbandingkan dengan data-data yang sesungguhnya (Tenenhaus et al., 2004). Uji untukGoodness of Fit ke inner model dengan cara dipakainya nilai predictive relevance $\left(\mathrm{Q}^{2}\right)$. Nilai untuk Q-squarenya harus besarannya lebih dari 0atau nol, ini akan menunjukkan pada model imi sudah memiki nilai pada predictive relevance. Nilai Rsquare $\left(\mathrm{R}^{2}\right)$ ke masing-masing variabel endogen didalam penelitian ini bisa dilihat dalam perhitungan ini: 
Nilai untuk predictive relevancedapatdidapatkan dengan memakai rumusan :

$Q^{2}=1-(1-R 1)\left(1-R_{p}\right)$

$Q^{2}=1-(1-0.941)$

$Q^{2}=1-(0.059)$

$Q^{2}=0.941$

Hasil yang didapat dari perhitungan diatas sudah memperlihatkan untuk nilai predictive relevance $0,941>0$, ini berarti bahwa model ini dikatakan layak untuk memiliki nilai prediktif yang relevan.

Nilai dihasilkanpada ujian dihipotesiskan (Estimasikan pada Koefisien Jalurnya). Nilai untuk estimasi pada hubungan suatu jalur didalam model untuk struktural diharuskanbersignifikan. Nilai signifikanakan bisa didapatkan dengan cara prosedurnya melauiboostrapping.Untuk dapat melihatkan signifikan di hipotesis,cara melihatnya dinilai koefisien parameter dan juga pada nilai signifikan Tstatisticyang harus lebih besar dari 1,96 (Ghazali, 2014). Terjadinya signifikansi atau tidak signifikan, ini dapat dilihat padaTtabelalpha0,05 tau 5\% = 1,96, seterusnya untukT tabelakan diperbandingkan dengan $\mathrm{T}$ hitung atau $\mathrm{T}$ statistik. Hasil untuk uji hipotesis dengan carapath coefficients dan boostrapping ada dibawah ini:

\section{Hasil Uji Hipotestis}

Tabel 12. Uji Hipotesis

\begin{tabular}{l|c|c|c|c|c}
\hline \multicolumn{1}{c|}{ Variabel } & $\begin{array}{c}\text { Original } \\
\text { Sample } \\
(\mathbf{O})\end{array}$ & $\begin{array}{c}\text { Sample } \\
\text { Mean } \\
(\mathbf{M})\end{array}$ & $\begin{array}{c}\text { Standart } \\
\text { Deviation } \\
(\text { STDEV) }\end{array}$ & $\begin{array}{c}\text { T Statistcs } \\
\text { (O/STDEV) }\end{array}$ & P Values \\
\hline $\begin{array}{l}\text { Fasilitas -> Kepuasan } \\
\text { pelanggan }\end{array}$ & 0.832 & 0.834 & 0.051 & 16.184 & 0.000 \\
\hline $\begin{array}{l}\text { Kepercayaan -> Kepuasan } \\
\text { Pelanggan }\end{array}$ & 0.194 & 0.194 & 0.034 & 5.719 & 0.000 \\
\hline $\begin{array}{l}\text { Kualitas Pelayanan -> } \\
\text { Kepuasan Pelanggan }\end{array}$ & -0.028 & -0.030 & 0.050 & 0.549 & 0.583 \\
\hline
\end{tabular}

Sumber: Olah Data (2020) 


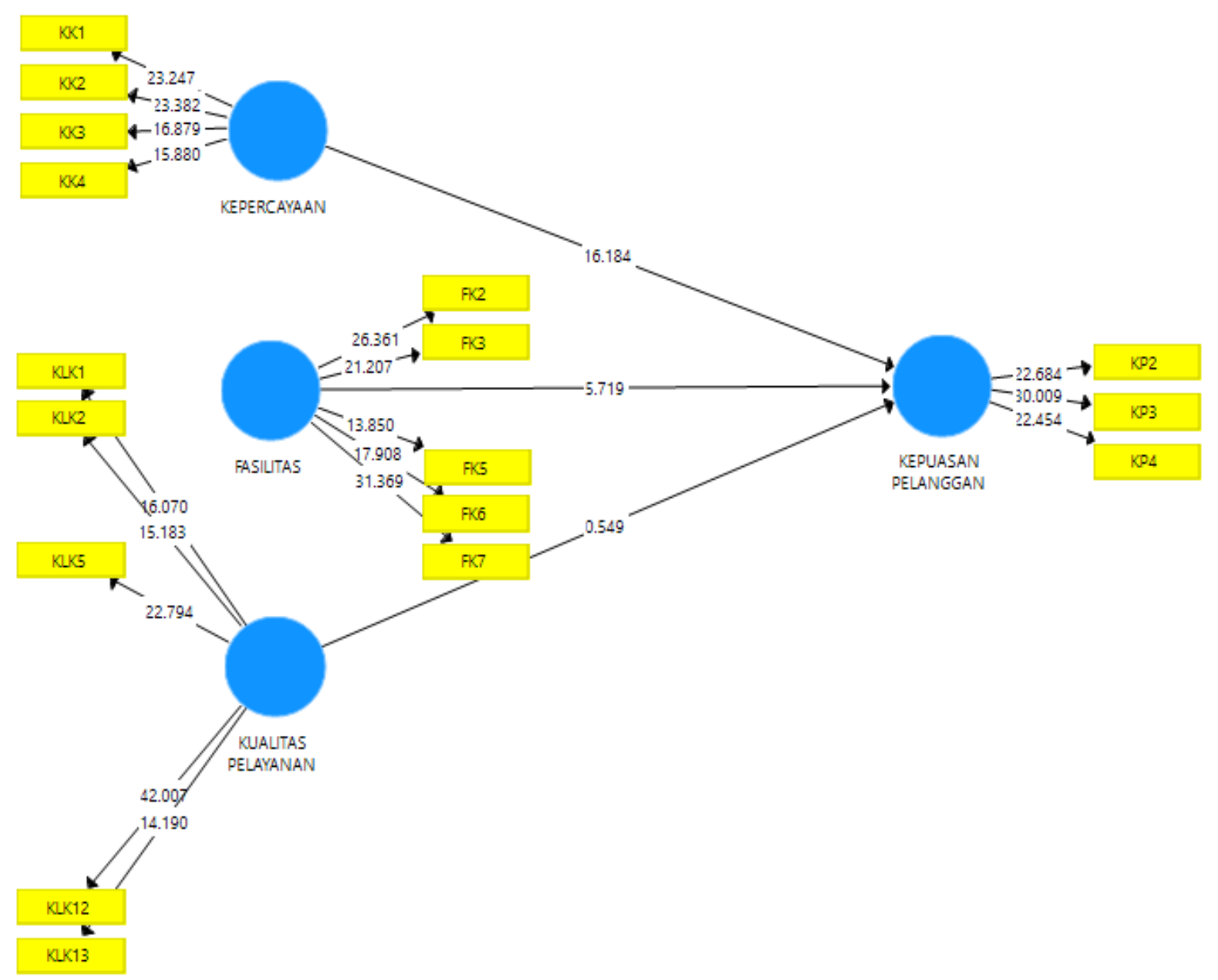

Gambar 2. Hasil Output Diagram Jalur Awal

Sumber: Output PLS (2020)

Menunjukkan hasil bahwa kepercayaan akan ada pengaruh yang positif juga signifikan kepada kepuasan pelanggan, yang ditunjukkan oleh nilai t-hitung: 16,184 melebihi besarnya dari pada t-tabel 1,96 dengan memiki tingkat kesalahan 0,05 (5\%). Nilaikeoriginal sampel :sudah berpositif sebesar 0,832berarti menunjukkankearah hubungan diantara keterjangkauan kepercayaan dengan kepuasan pelanggan adalah telah positif, untuk variabel fasilitas juga memiliki pengaruhyang sudah positif juga signifikan kepada kepuasan ke pelanggan, ini ditunjukkan dengan nilai t-hitungnya5,719 dan lebih besar dibandingkan dengan t-tabel 1,96 dengan tingkat kesalahannya 0,05, dengan nilaioriginal sampel yang positif yaitu nilainya 0,194 telah menunjuk kearah hubungan diantara fasilitas kepada kepuasan pelanggan adalah sudah positif. Pada kualitas pelayanan pengaruhnya adalah positif tetapi kurang signifikan terhadap kepuasan pelanggan, hal ini dapat dilihat dari t-hitungnya 0,549 lebih kecil dari t-tabel sebesar 1,96 dengan nilai tingkat untuk kesalahan 5\%,dimananilai keoriginal sampelnya negatif yakni -0,028 dimanaarah hubungan antara kualitas pelayanan kepada kepuasan pelanggan adalah negatif. 


\section{PEMBAHASAN HASIL PENELITIAN}

Berdasarkan hasil analisis menggunakan PLS (Partial Least Square) maka selanjutnya peneliti akan melakukan pembahasan mengenai analisis yang sudah dilaksanakan. Penelitian untuk mengetahui pengaruhnya pada variabel fasilitas, kepercayaan, kualitas pelayanan terhadap variabel kepuasan pelanggan pada Perusahaan Multi Finance. Untuk mengetahui pengaruhnya maka dilakukan pengujian hipotesis sehingga dapat diketahui saling berpengaruhnya suatu variabel dengan variabel lainnya.

Pengaruh Kepercayaan terhadap Kepuasan Pelanggan. Berdasarkan hasil uji statistik deskriptif kepercayaan terdapat nilai tertinggi pada indicator KK5 (Multi Finance memiliki kejujuran dalam menerapkan harga atau bunga kredit) untuk nilai mean 3.559 dan nilai nilai deviasi 0.804 dan Nilai terendah pada indicator KK1 (Pelanggan yakin dengan tanggung jawab perusahaan Multi Finance) untuk nilai mean 3.538 dan niilai standart deviasi 0.675. Untuk uji hipotesis pada penelitian ini memperlihatkan kepercayaan adapengaruhnya yang positif juga signifikan pada kepuasan pelanggan. yang dapat ditunjukkan oleh nilai di t-hitung 16,184 lebih besar daripada t-tabel 1,96, memiki tingkat kesalahan $0,05(5 \%)$. Nilai untuk original sampelsudah positif besarnya 0,832 , berarti menunjukkan kearah hubungan diantara keterjangkauan kepercayaan terhadap kepuasan pelanggan telah positif. Hasil penelitian ini telah memperkuat penelitian yang sudah (Purwa dan Ardani, 2018) yang menyatakan untuk variabel kepercayaan ada pengaruhnya positif juga signifikan terhadap kepuasan pelanggan. Diperkuat juga oleh (Shafique et al., 2015). Kepercayaan telah berpengaruh secara positif dan juga signifikan kepada kepuasan pelanggan. Penelitian lainnya (Chhabra, 2018) untuk variabel pada kepercayaannyatelah berpengaruh yang berpositif serta signifikanspadakepuasan pelanggan. Kepercayaan merupakan faktor yang penting untuk menciptakan rasa percaya dan yakin terhadap pelanggan setiap bertransaksi di Multi Finance.

Pengaruh Fasilitas terhadap Kepuasan Pelanggan. Berdasarkan hasil uji statistik deskriptif fasilitas terdapat nilai tertinggi pada indicator KLK1 (Karyawan Multi Finance melayani konsumen dengan maximal) untuk nilai mean 3.697 dan nilai nilai deviasi 0.825 dan Nilai terendah pada indicator KLK5 (Karyawan Multi Finance menyelesaikan keluhan pelanggan dengan cepat) untuk nilai mean 3.559 dan nilai standart deviasi 0.673 . Untuk Uji hipotesis memiliki hasil untuk variabel fasilitas juga memiliki pengaruh positif dan signifikan kepada kepuasan pelanggan, dengan nilai t-hitung sebesar 5,719 dan lebih besaran dari t-tabel 1,96, pada tingkat kesalahannya $0,05 / 5 \%$, dengan nilai originalitas sampel yang positif yaitu nilainya besarnya 0,194,telah melihatkan arah untuk hubungan antara fasilitas pada kepuasan pelanggan adalah sudah positif.Hasil penelitian ini akan memperkuat untuk penelitian (Jamal dan Dandis, 2018). Pada variabel fasilitas memiki pengaruh positif dan juga signifikan terhadap kepuasan pelanggan, juga untuk (Akbarezky dan Eko, 2019) memiliki pendapat di variabel fasilitas ada pengaruhnya positif serta signifikan ke kepuasan pelanggan. Fasilitas merupakan suatu faktor penting yang dapat mempengaruhi kepuasan para pelanggan, dengan adanya fasilitas membuat mereka nyaman dan menjadi nilai tambah bagi para konsumen. 
Pengaruh di Kualitas Pelayanan terhadap Kepuasan Pelanggan. Berdasarkanpada hasilnya, uji statistik deskriptif kualitas pelayanan terdapat nilai tertinggi pada indicator FK5 (Seragam karyawan yang menarik perhatian pelanggan) untuk nilai mean 3.559 dan nilai nilai deviasi 0.804 dan Nilai terendah pada indicator FK1 (Penempatan perabot dalam ruangan tunngu pelanggan sangat rapih pada Multi Finance) untuk nilai mean 3.538 dan nilai nilai deviasi 0.675. Pada uji hipotesis pada penelitian ini menunjukkan padavariable kualitas pelayanan pengaruhnya adalah positif tetapi kurang signifikan terhadap kepuasan pelanggan, hal ini terlihat dari t hitung besarnya 0,549 lebih kecilnya dari t-tabelnya sebesar 1,96, dengan nilai untuktingkat kesalahannya 0,05 / 5\%,dengannilai keoriginal sampelnya yang negatif nilainya $-0,028$ dimana ini menunjukkan bahwa untuk arah hubungan antara kualitas pelayanan kepada kepuasan pelanggan adalah negatif. Hasil penelitian ini menambah penguatan pada penelitian Dorce Dahlia, H. Mulyadi, Sarwo Eddy Wibowo (2019) yang mengungkapkan bahwa variable kualitas di pelayanan miliki efeknegatif dan juga tidak signifikan terhadap kualitas pelayanan, juga untuk penelitian lainnya oleh Yenni (2018) untuk kualitas pelayananpengaruh secara negatif dan tidak signifikan kepada kepuasan pelanggan, serta memperkuat penelitian Cornelius Prihandono (2019) pada kualitas layanan mempengaruh negatif serta tidak signifikan ke kepuasan pelanggan.

\section{KESIMPULAN}

Atas dasar hasil analisis yang sudah dilaksanakan didalam penelitian ini, dapat diambil kesimpulannya: (1) Variabel Kepercayaan pengaruh positif dan signikan terhadap kepuasan pelanggan Multi Finance Tangerang. Untuk kepercayaan ini merupakan faktor yang penting dalam menciptakan rasa percaya dan yakin terhadap pelanggan setiap bertransaksi. (2) Fasilitas memiki pengaruh yang positif dan juga signifikan terhadap kepuasan pelanggan Multi Finance Tangerang. Fasilitas adalah faktor penting yang mempengaruhi kepuasan pelanggan, dengan adanya fasilitas membuat mereka nyaman dan menjadi nilai tambah bagi para pelanggan. (3) Kualitas Pelayanan berpengaruh kearah positif tetapi kurang signifikan untuk kepuasan pelanggan Multi FinanceTangerang. Kualitas untuk pelayanan adalah faktor tidak terlalu memiliki peranan untuk menciptakan rasa puas terhadap pelanggan.

Saran. Pembahasan dan kesimpulan berdasarkan diatas, memberi saran yang dijadikan acuan dan pertimbangan dari penelitian ini: (1) Perusahaan tetap harus komitmen menjaga kepercayaan baik dari segi karyawan dan kepercayaan yang diberikan langsung para pelanggan. (2) Perusahaan akan menambahkan fasilitas lain selain kursi yang nyaman seperti TV, jadi pelanggan bisa menonton TV sambil menunggu antrian. (3) Perusahaan agar memperbaiki dengan cara memberi sanksi jika ada karyawan tidak jujur dalam bertransaksi. (4) Peneliti selanjutnya disarankan untuk menambahkan variabel penelitian lainnya misalnya lokasi, motivasi atau promosi yang terkait mempengaruhi kepuasan pelanggan. 


\section{DAFTAR PUSTAKA}

Akbarezky, R., dan Santoso, E. B. (2019). Pengaruh Harga dan Fasilitas terhadap Kepuasan Konsumen Mie Setan Malang. Jurnal Aplikasi Bisnis, 270-273.

Arief Bowo Prayoga Kasmo. (2017). The Influence Social Media on Buying Intention of MSME's Product (Case Study of Chips Talas Dessy). Prosiding seminar Nasional Ekonomi V 2017.

Chen, B.-L., and Rashid , M. Z. (2018). Service Quality and the Mediating Effect of Corporate Image on the Relationship between Customer Satisfaction and Customer Loyalty in the Malaysian Hotel Industry. Gajah Mada International Journal of Business, 99-112.

Chhbra, K. (2018). Analysis of India's Internet Banking Customer's Perception Regarding Service Quality, Trust, Satisfaction and Loyalty. Journal of Commerce \& Accounting Research, 52-60.

Dahla, D., Mulyadi, H., dan Wibowo, S. E. (2019). Pengaruh Kualitas Pelayanan dan Kepercayaan Terhadap Kepuasan Pelanggan pada Tiki Cabang Utama Samarinda. Jurnal Bisnis Manajemen, 1-12.

Ghoali, I., dan Latan, H. (2014). Partial Least Squares Konsep, Teknik dan Aplikasi menggunakan Smart PLS 3.0. Semarang: Universitas Diponegoro Semarang ISBN : 979.704.300.2.

Hair J. F., Hult, G. T., Ringle, C. M., dan Sarstedt, M. (2014). A Primer on Partial Least Squares Structural Equation Modeling (PLS-SEM). USA: SAGE Publication, Inc. .

Indrjaya, S. (2019). Culinary Tourism Analysis at Restaurant with Tourism Satisfaction Mediation . European Research Studies Journal Volume XXII, Issue 3.

Indajaya, S. (2020). The Effect of Online Transportation on Multiple Shopping Habits that Give Loyalty. Advance in Economics, Business and Management Research, Volume 144, 369-375.

Keller, K. (2013). Strategic Brand Management. 4th Person Harlow.

Khudhair, H. Y., Jusoh, A., Mardani, A., and Nor, K. M. (2019). Quality Seekers as Moderating Effect between Service Quality and Customer Satisfaction in Airline Industry. International Review of Management and Marketing, 74-79.

Lai, D. C.-S., and Nguyen, M. C. (2017). Factors Affecting Service Quality, Customer Satisfaction and Loyalty pf Mobile Phone Service Providers in Vietnam. International Journal of Organization Innovation, 75-85.

Minh, N. V., and Huu, N. H. (2016). The Relationship between Service Quality, Customer Satisfaction and Customer Loyalty: An Investigation in Vietnamese Retail Banking Sector. Journal of Competitiveness, 103-116.

Moh, S., dan Loindong, S. (2016). Analisis Kualitas Pelayanan dan Fasilitas terhadap Kepuasan Konsumen pada Hotel Yuta di Kota Manado. Jurnal Riset Ekonomi, Manajemen, Bisnis dan Akuntansi, 575-584.

Nugroho, A., dan Magnadi, R. H. (2018). Pengaruh Kualitas Pelayanan terhadap Kepuasan Pelanggan Jasa Pengiriman Lazada Express Saat Harbolnas di ECommerce. Diponegoro Journal of Management, 1-11. 
Pantiu, D., Koleangan, R. A., dan Roring, F. (2018). Pengaruh Kualitas Pelayanan, Harga dan Fasilitas terhadap Kepuasan Pelanggan pada Warunk Bendito Kawasan Megamas Manado. Jurnal Riset Ekonomi, Bisnis dan Akuntansi, 3723-3732.

Pradana, F. (2018). Pengaruh Manajemen Hubungan Pelanggan, Kualitas Pelayanan, dan Kualitas Pengalaman terhadap Loyaliyas Pelanggan dengan Kepuasan Pelanggan Sebagai Variabel Intervening pada Nasabah PT. FAC Sekuritas Indonesia di Yogyakarta. Jurnal Manajemen Bisnis, Vol.9 No. 2 September 2018, 193-212.

Prihndono, C. (2019). Pengaruh Kualitas Pelayanan terhadap Kepuasan Pelanggan JNE Cabang Balikpapan . Jurnal Geo Ekonomi, 116-129.

Purw I. B., dan Ardani, I. G. (2018). Peran Kepercayaan Nasabah dalam Memediasi Pengaruh Kualitas Pelayanan terhadap Kepuasan Nasabah. E-Jurnal Manajemen Unud, 192-220.

Rambat, L. (2014). Manajemen Pemasaran Jasa. Jakarta: Salemba Empat.

Shaique, M. N., Ahmad, N., and Hameed, M. (2015). Hypothetical Development Among E-Service, Customer Satisfaction and Brand Trust in Pakistan. Arabian of Business and Management Review, 34-41.

Suiono. (2015). Metode Penelitian Bisnis (pendekatan kuantitatif, kualitatif dan R\&D). Bandung : Alfabeta.

Shana, A., Eldine, A., dan Sume, S. A. (2019). Citra Merek dan Fasilitas (Tangible) terhadap Kepuasan Pelanggan. Jurnal Ilmu Manajemen, 103-113.

Tjiptono, F. (2015). Strategi Pemasaran. Yogyakarta: Edisi 4 Andi.

Tjipto, F., and Gregorius, C. (2016). Service, quality and satisfaction. Yogyakarta: Andi.

Wanra, P. (2015). The Relationships among Service Quality, Customer Satisfaction, and Customer Loyalty in Library Service. International Journal of Economics and Finansial Issues, 264-269.

Winarno, S., Mananeke, L., dan Ogi, I. W. (2018). Analisis Pelayanan Konsumen dan Fasilitas terhadap Kepuasan Konsumen Kedai Kopi Maxx Cofee Cabang Hotel Aryaduta Manado. Jurnal Riset Ekonomi, Bisnis dan Akuntansi, 1248-1257.

Yen. (2016). Pengaruh Kualitas Pelayanan terhadap Kepuasan Pelanggan pada PT. PLN (Persero) Unit Pelaksana Pelayanan Pelanggan (UP3) Makassar Selatan. Jurnal Bisnis dan Ekonomi, 1-26.

Yuli Arwani, Aprilia Aska Sakinah. (2020). The Influence of Brand Awareness, Packaging Design and Word of Mouth on Purchase Intention. Advances in Economics, Business and Management Research. 